\title{
Adolescent Substance Abuse and Family Environment: A Qualitative Study
}

\author{
Peyman Moradi ${ }^{1,{ }^{*}}$, Fahimeh Fathali Lavasani ${ }^{1,2,{ }^{* *}}$ and Masoumeh Dejman ${ }^{3,4}$ \\ ${ }^{1}$ School of Behavioral Science and Mental Health, Iran University of Medical Sciences, Tehran, IR Iran \\ ${ }^{2}$ Research Center for Addiction and Risky Behaviors, Iran University of Medical Sciences, Tehran, IR Iran \\ ${ }^{3}$ Department of Mental Health, Johns Hopkins Bloomberg School of Public Health, Baltimore, United States \\ ${ }^{4}$ Amarex Clinical Research, Germantown, United States \\ "Corresponding author: School of Behavioral Science and Mental Health, Iran University of Medical Sciences, Tehran, IR Iran. Email: peymanmoradi.ir@gmail.com \\ "Corresponding author: School of Behavioral Science and Mental Health, Iran University of Medical Sciences, Tehran, IR Iran. Email: lavasani.f@gmail.com \\ Received 2018 August 31; Revised 2019 March 06; Accepted 2019 March 16.
}

\begin{abstract}
Background: Substance abuse has always been one of the major health concerns in Iran. Substance abuse during adolescence has a range of negative consequences for the individual. Earlier studies in Iran mainly focus on the epidemiology of substance abuse among adolescents and few studies have focused on its underlying factors.

Objectives: This study was aimed to explain the family factors underlying the development of a tendency for substance abuse among adolescents.

Patients and Methods: This is a qualitative study, and the conventional content analysis method was used. The participants consisted of 12 people who were selected using purposeful sampling method. They were the adolescents in Tehran Province Youth Detention Center in Iran with previous or current experience of substance abuse in the age range of 15 - 19 years old. Data were collected through in-depth interviews. The interviews were transcribed verbatim and the data were analyzed using qualitative content analysis.

Results: Four themes were obtained based on the research goal: Paternal role, maternal role, discipline methods, and family function. The paternal role consisted of three categories of insufficient paternity, passive paternity, and lack of paternity. The maternal role was comprised of incompetent maternity, and lack of maternity. The discipline methods were composed of three categories of punitive discipline, enhancing affection, and inadequate supervision. Finally, the family function referred to a blaming and unsupportive family.

Conclusions: Substance abuse prevention programs for vulnerable teenagers will have better outcomes by involving their parents, particularly their fathers. Also, it seems the mental health and addiction policymakers need to prioritizing family education as one of the most important substance abuse prevention strategies in vulnerable adolescents.
\end{abstract}

Keywords: Adolescent, Substance-Related Disorders, Family Health, Rehabilitation Center

\section{Background}

Substance abuse is one of the major concerns of public health in the world (1), especially Iran. In fact, Iran is the neighbor of two main opium-producing countries named Afghanistan and Pakistan. According to the United Nations Office on Drugs and Crime (UNODC) (2), the largest opioid discovery reports in the world was in 2014 in Iran. Consequently, $75 \%$ of total opium, $61 \%$ of total morphine, and $17 \%$ of total heroin have been seized in Iran.

Various factors affecting substance abuse are in three levels of individual, family, and the environment. Sensitivity to reward (STR) $(3,4)$, adverse experiences of childhood, externalizing behaviors and relevant disorders (5), destructive and aggressive behaviors (6), as well as traumatic experiences during childhood such as child abuse (7), and also poverty (2), access to drug in the district where the person lives, and peer substance abuse are the known risk factors for substance abuse (8). Among the socioenvironmental factors, the family is very important. It is the first social environment that the child has experienced, which is highly important to reduce the risk factors and to protect them against environmental hazards (9). Studies have shown that family-centered interventions could have many benefits (10). A family can be effective in preventing adolescent substance abuse by reducing the risk factors or promoting protective or resilience factors (11). The evidence has suggested that the authoritative parenting style 
(12), secure parent-child attachment (13), and parent supervision (14) can protect the youth from drug use. Moreover, parental drug use is considered to be one of the major risk factors for adolescent drug use $(15,16)$.

Although several studies have pointed out the role of family and its importance in substance abuse among adolescents, and numerous prevention programs have been designed and implemented focusing on the family environment, for example, strengthening family program (SFP) and preparing for drug-free years (PDFY), or problem solving education (PSE) (17), the underlying factors of tendency to substance abuse have not been completely studied. Some studies have focused on the role of parents and their drug use (18), and others have studied the childhood traumatic experiences (19).

\section{Objectives}

Meanwhile, fewer studies have examined the family environment from the point of view of adolescent drug users. The present research was aimed to investigate the family environment from the adolescent drug user's perspective.

\section{Patients and Methods}

In this research, a qualitative approach and a conventional content analysis method (20) were used. The qualitative research method according to Strauss et al. (21) is the most appropriate method for discovering the meaning behind human behaviors and experiences. This research was approved by the Ethics Committee, Iran University of Medical Sciences under code 9311556008.

\subsection{Participants}

The participants in this study were adolescents at the Youth Detention Center, which is a place for the maintenance, training, and disciplining of juvenile delinquents under the age of 18 (recently under the age of 24 years old). The participants were selected purposefully according to the research criteria. The inclusion criterion was the experience of substance abuse and the exclusion criterion was the lack of family life experience. In this study, the in-depth interviews were used for data collection and, due to the personal nature of the questions, the interview was conducted individually. The number of interviews was determined based on the principle of saturation. Therefore, 12 interviews were conducted with the adolescents. All the interviews were audio-recorded according to the ethical considerations and written informed consent was obtained from the participants.

\subsection{Data Collection and Analysis}

All the interviews began with an opening question: "Why did you come to the center? Tell me the story, I am listening". Then the main question was asked about "the quality of interaction between participants and their families". All the next exploratory questions, including probing and follow-up questions, focused on this question.

Based on the qualitative content analysis method (20), the initial process of data analysis (transcription, repeated reading, and extraction of meanings) was made immediately after each interview. Then the codes were extracted using the first concepts and highlighted thoughts. By taking into account of the first conceptions and thoughts as well as initial analysis of the interviews, the meaning of the original text was found. Also, during the data collection, the existing data gap was recorded as a memo, thus the additional interviews were made to examine the noted issues and further reflection on data collection. Then, after data saturation (22), the final categorization and analysis of the themes were made. Subsequently, based on the relationship of codes with each other, they were classified as themes. These themes were classified as meaningful clusters for the organization and categorization of codes (table or figure, etc.). In order to validate the research findings, the research codes were frequently examined by other members of the research team (23).

\section{Results}

Table 1 shows the demographic characteristic of the participants.

\begin{tabular}{|cc}
\hline Table 1. Demographic Characteristics of the Participants & \\
\hline Variables & No. $(\%)$ \\
\hline Age group, $\mathbf{y}$ & $1(8)$ \\
\hline 16 & $6(50)$ \\
\hline 17 & $4(34)$ \\
\hline 18 & $1(8)$ \\
\hline 19 & \\
\hline Level of education & $2(17)$ \\
\hline Elementary school & $7(58)$ \\
\hline Middle school & $3(25)$ \\
\hline High school & $12(100)$ \\
\hline Total &
\end{tabular}

The content analysis of the transcripts for the concept of the family revealed three themes, each containing several subcategories (Box 1). Themes and their subcategories are described below. 


\begin{tabular}{|l}
\hline Box 1. Emerging Themes and Subcategories \\
\hline Emerging Themes/Subcategories \\
\hline Paternal role \\
Passive paternity \\
Insufficient paternity \\
Lack of paternity \\
\hline Maternal role \\
\hline Incomplete maternal role \\
\hline Lack of mother \\
\hline Disciplining methods \\
Punitive discipline \\
Enhancing affection \\
\hline Inadequate discipline \\
\hline
\end{tabular}

\subsection{Paternal Role}

Regarding the paternal role, the participants pointed out the father's passivity, his insufficient parenting, or the lack of paternal role.

\subsubsection{Passive Paternity}

Most participants experienced a passive involvement of father in the parenting process so that the father had not a tangible presence in the discipline process. For example, the father had abandoned his responsibilities and had assigned all the duties of disciplining (such as supervision and advice of the offspring child) to the mother and did not interfere with it.

“...My mother paid a lot of attention to me, whereas my father ..., I came home at $10 \mathrm{pm}$, and she was sitting on the stairs waiting for me, while he was asleep...."

\subsubsection{Insufficient Paternity}

This subcategory particularly described the interaction and involvement of father in the discipline process of teen boys. Considering the role and function of the father, the participants reported that the father was an important factor in disciplining and his more involvement in the supervision and discipline process could play an important role in preventing substance abuse. According to the experience of some of the participants, despite the involvement of their father in the parenting, his presence was not sufficient.

“...Our father wanted to give us advice, but he was not around... He was always at work until late and, when he came back, he slept. My brother goes to university, thus my father is working to pay his tuition fees; when he came home, he was tired and slept" (7th participant).

\subsubsection{Lack of Paternity}

A number of adolescents had experienced a lack of paternal role.

"My father died when I was only 2 years old; however, we did not find out whether he died and we could not find him at all. We searched a lot".

Furthermore, some of the participants reported that their fathers not only were responsible for but also encouraged them to use drugs.

"My father led me this way; I was 10 years old when my father gave me hookah. Although he was very mad once he noticed that I had become an addict, he took me somewhere to find drugs the same night".

"...I took drugs with my father for the first time... Later, I began drinking as well and used opium. My friend brought heroin to our home; he used to come to our home and smoke with us. One day he came to our home and I was preparing to make aluminum foil for heroin use.... My friend added heroin and used it. Then my father did so and, later, and I did it and started to like it" (8th participant).

\subsection{Maternal Role}

\subsubsection{Incompetent Maternal Role}

The most prominent code in this category that closely related to insufficient and passive paternity was incompetent maternal role. According to the participants, where the father was not a source of power, the mother was not able to exercise power, which was associated with the lack of order and rules at home.

"My mother did not know I was taking meth. I was out until late at night when I came back and changed my clothes. She could not do anything. How can a lonely woman do such a thing?"

"I did not listen to her and she could not do anything. She had not the power".

\subsubsection{Lack of a Mother}

Some of the participants had experienced the lack of the mother. Some had lost their mothers and others were living with their fathers after divorce and they had not seen their mothers for a long time. They believed that the mother has a more protective role than the father and could provide more emotional support and care. Therefore, according to the participants, lack of a mother meant inadequate care and supervision. These adolescents imagined another future for themselves if they could live along with their mothers.

"Mother has a kind of understanding...She makes us relax by her words...She pays a lot of attention to her children and would stop them from going toward the drugs...But I had no one to share my feelings and my pains 
with her...I had no other choice except for drugs..." (4th participant).

\subsection{Disciplining Methods}

\subsubsection{Punitive Discipline}

Another category in the family relationship is discipline that pointed out the range of disciplining methods of the parents. According to the adolescents, discipline was the most important factor in the tendency to the drugs. One of the most common discipline methods that participants reported was punishment. Participants noted this discipline method destroyed their sense of dignity and self-esteem with no effect on their behavior.

"I was beaten constantly by my parents. They were destroying my character in front of my friends. They beat me up and scolding. That's where I learned to curse".

\subsubsection{Enhancing Affection}

On the other hand, one of the discipline methods reported by adolescents was enhancing affection of parents so that after they found out that the adolescent uses drug, they increased their affection and paid more attention to him. This behavior could include more pocket money and leniency for the adolescent, which on the contrary, led to more drug use.

"I was welcomed at home. They provided me with good conditions. After coming back from work, I could do anything. They even had not any problems with my smoking. They got used to it. [They] said, 'smoking is ok, but do not go to the drugs'. My mother even bought me cigarettes sometimes".

\subsubsection{Inadequate Supervision}

Another subcategory in the disciplining methods was supervision. This category refers to the ways of supervising the adolescents both before and after drug use by parents. Many of the adolescents said that no supervision was carried out by parents, and some others expressed the desire for more supervision.

"My grandma could ask the grocery store whether I bought cigarettes or not. She could ask my friends; at least one of them could have been a rat and told her. Even when the neighbors told her about me, she did not believe them. She thought I was a saint. She argued with neighbors. She told them not to label me. So I found that she would not suspect me and I went on...." (2nd participant).

In other cases, the supervision was poor and insufficient, for example the parents would say something with no follow-up.

"I said that he is not a bad friend, you just think so. I have been hanging out with him for all these years, and nothing has happened to me. She did not know I am taking drugs. Sometimes, she told me 'don not hang out with him', but I did not care. She did not follow-up. She was not so persistent. She said something once, but she would not say anything if she saw us together on the part. My mother knew my other close friends since my school time".

In some cases, the adolescents reported that supervision was done incorrectly and the parents had inappropriate criteria for supervision. For example, since the parents knew the mother or father of friends of their children, they reassured and did not implement enough supervision. For example, one of the participants referred to working with his uncle who was a drug user. His mother let his son work there merely because the uncle was a familiar relative, while the drug use began exactly afterward. There were parents who, instead of forbidding hookah use, would even offer a better hookah house to their children.

"I went to a hookah house. They knew I am going there. They said hookah is not something dangerous. They only told me to go to a better hookah house with better people".

"I was wrong with my father. My family did not take it so hard. My mother did, but not my father. I was 10 years old when my father let me use the hookah".

\subsection{Family Function}

In addition to emphasizing parental supervision and discipline, adolescents pointed out the supportive role of the family. It is important to note that some adolescents referred to the family and its role in a contradictory manner. Sometimes, the adolescents did not directly blame their family, but noted they did not use drug if family had more care and support. For example, one of the participants said, "in case of family care (in particular, the mother), I would never use the drugs".

Importantly, to answer the question "How would you prevent your future children from drug use?" almost all of them pointed out a close relationship with their children as well as providing guidance and support for them.

"I would not let him go to the strangers, but come to me. I would provide everything he needs. I would not let him go out much. I would make him get used to staying home. I would not let him hang out with bad people, unlike my father. My mother knew I was going astray, but she could not stop me. She could not do anything on her own".

"I would teach him from the beginning not to go to the drugs; something my parents did not. They did not tell me that drugs are bad. My father told me that when I had already become an addict, but not before". 


\section{Discussion}

The aim of this study was to examine the role of family environment in substance abuse among a group of vulnerable adolescents. Most of the adolescents in this study were living in socio-economically poor neighborhoods, where the drug use and its various consequences such as involvement in crimes, (e.g. theft, drug trafficking,) and homelessness were prevalent. It is precisely at this stage that the criminal justice system detects juvenile offenders and refer them to the correctional system. However, it seems to be more effective to identify family risk factors for drug use (parental separation and divorce, the presence of a drug user in the family, and passive involvement of fathers in parenting) and designing and implementing family-based preventive interventions for this group of atrisk teens.

The results of this study show the family is a highly important factor in tendency to drug abuse among adolescents, whether there is a drug user in the family or parental behavior facilitating such a tendency (24). Thus these results highlight the importance of family involvement in preventive and therapeutic interventions, both in the correction and rehabilitation centers and in living environment. First, it should be noted that risk factors interact with each other to affect drug use behaviors. For example, all the participants were living in neighborhoods with a high rate of substance abuse and drug trafficking. They also frequently were related to drug users who ranged from the presence of drug users in the family to drug user friends or coworkers.

The findings of the present research revealed that a range of adverse family and environmental experiences act as risk factors and increasing risk of substance abuse. Most of the participants were living in the single-parent families. The children of these families, most of them were headed by single mothers, were highly prone to engaging in high-risk behaviors. Also, the lack of (active) presence of father and economic problems prevented the family from having enough time for the teens, which in turn could lead to poor supervision and increased risk of children's involvement in high-risk behaviors (25).

From the perspective of mental health and well-being, the children and adolescents have higher priority than their parents, while from the perspective of addiction treatment; the drug user will have priority. Due to the relatively high prevalence rate of substance abuse in the family of participants, neglecting the adolescents and other members of these families by mental health structures, which is called the "difference in professional view" (26), should be considered. The paternal and maternal roles are regarded as two different, but effective functions from in comparison to each other $(27,28)$. According to Biblarz and Stacy, fathers play an effective role in shaping their son's masculine identity and preventing them from engaging in delinquent behaviors. Girls also need a father to consider their femininity. According to Hagan et al. (29), families are more interested in restricting girls' behaviors than boys', and boys have more relative freedom. Once this relative freedom is accompanied by inadequate monitoring, the risk of engaging in high-risk behaviors is increased significantly, which is in agreement with the unstructured socialization theory (30).

One of the most important factors in drug use by participants was the soothing function of drugs. Along with the self-treatment hypothesis of Khantzian (31) the probability of adolescent substance abuse increases in stressful family environment (such as punitive parenting or frequent residence changes) and failure of family in providing peace and solution for stress reduction. Thus the substance abuse could be regarded as a coping style or an escape mechanism (32-34). Among the most common risk factors were reported by participants were school dropout and consuming gateway drugs such as cigarettes and hookahs. Numerous studies have noted the relationship between dropout and academic failure with drug use (35). Based on the social control theory, when bonds with society include school are weakened, control mechanisms for deviant behavior also becomes ineffective; therefore, people will have a high tendency toward behaviors that are not socially acceptable (36).

Finally, most participants were attended the addiction treatment camps for substance abuse treatment; on the contrary, the camps not only lead to return to drug use, but also makes them familiar with other drugs and the various methods of drug abuse. Since those in the addiction treatment camps have a higher average age and their substance abuse patterns are high-risk, it is very likely the teenagers will model this pattern of substance abuse after discharge from the camp.

This study had some limitations. Based on the rules of juvenile detention center, there was no access to the adolescents' files. Thus the psychologists of the center checked the inclusion criteria and they chose the participants. Moreover, the lack of long-term contact with the participants, which is suggested in qualitative research to increase the validity of research, was another limitation in this study.

\subsection{Conclusions}

Since this was a qualitative study, the results led to a better understanding of the factors affecting the tendency for drug use from the point of view of adolescents. These results emphasized the role of father in tendency toward 
drugs when the paternal function was insufficient and invisible in the discipline. Similarly, the mothers were not capable of being strict disciplinarians, in part because of less power and influence. However, it seemed the mothers paid more attention to supervision and discipline. The findings of this research emphasized the role of parenting in protecting adolescents from drug use. Finally, the results suggest that families living in disadvantageous neighborhoods with a high prevalence of drug use as well as families with a drug user should have a higher priority in implementing prevention programs.

\section{Footnotes}

Authors' Contribution: Study concept and design: Peyman Moradi, Fahimeh Fathali Lavasani, and Masoumeh Dejman; acquisition of data: Peyman Moradi; analysis and interpretation of data: Peyman Moradi; drafting of the manuscript: Peyman Moradi; critical revision of the manuscript for important intellectual content: Peyman Moradi, Fahimeh Fathali Lavasani, and Masoumeh Dejman; statistical analysis: N/A; administrative, technical, and material support: Masoumeh Dejman; study supervision: Fahimeh Fathali Lavasani and Masoumeh Dejman.

Conflict of Interests: The authors declare that there is no conflict of interest in reporting the results of this study.

Funding/Support: This study was conducted with no financial/material support.

\section{References}

1. Degenhardt L, Hall W. Extent of illicit drug use and dependence, and their contribution to the global burden of disease. Lancet. 2012;379(9810):55-70. doi: 10.1016/S0140-6736(11)61138-0. [PubMed: 22225671].

2. United Nations Office on Drugs and Crime (UNODC). Executive summary conclusions and policy implications. World drug report. United Nations Publications; 2017.

3. Blum K, Braverman ER, Holder JM, Lubar JF, Monastra VJ, Miller D, et al Reward deficiency syndrome: A biogenetic model for the diagnosis and treatment of impulsive, addictive, and compulsive behaviors. J Psychoactive Drugs. 2000;32 Suppl:i-iv. 1-112. [PubMed: 11280926].

4. Davis C, Strachan S, Berkson M. Sensitivity to reward: Implications for overeating and overweight. Appetite. 2004;42(2):131-8. doi: 10.1016/j.appet.2003.07.004. [PubMed:15010176].

5. King SM, Iacono WG, McGue M. Childhood externalizing and internalizing psychopathology in the prediction of early substance use. Addiction. 2004;99(12):1548-59. doi: 10.1111/j.1360-0443.2004.00893.x. [PubMed: 15585046].

6. Kellam SG, Brown CH, Poduska JM, Ialongo NS, Wang W, Toyinbo P, et al. Effects of a universal classroom behavior management program in first and second grades on young adult behavioral, psychiatric, and social outcomes. Drug Alcohol Depend. 2008;95 Suppl 1:S5-S28. doi: 10.1016/j.drugalcdep.2008.01.004. [PubMed: 18343607]. [PubMed Central: PMC2512256]

7. Dube SR, Felitti VJ, Dong M, Chapman DP, Giles WH, Anda RF. Childhood abuse, neglect, and household dysfunction and the risk of illicit drug use: The adverse childhood experiences study. Pediatrics. 2003;111(3):564-72. [PubMed: 12612237].
8. Guo J, Hawkins JD, Hill KG, Abbott RD. Childhood and adolescent predictors of alcohol abuse and dependence in young adulthood. $J$ Stud Alcohol. 2001;62(6):754-62. [PubMed: 11838912]. [PubMed Central: PMC1868672].

9. Sameroff AJ. Developmental systems and psychopathology. Dev Psychopathol.2000;12(3):297-312. [PubMed: 11014740].

10. Foxcroft DR, Tsertsvadze A. Universal family-based prevention programs for alcohol misuse in young people. Cochrane Database Syst Rev. 2011;(9). CD009308. doi: 10.1002/14651858.CD009308. [PubMed: 21901733].

11. Velleman RD, Templeton LJ, Copello AG. The role of the family in preventing and intervening with substance use and misuse: A comprehensive review of family interventions, with a focus on young people. DrugAlcohol Rev.2005;24(2):93-109. doi:10.1080/09595230500167478. [PubMed: 16076580].

12. Calafat A, Garcia F, Juan M, Becona E, Fernandez-Hermida JR. Which parenting style is more protective against adolescent substance use? Evidence within the European context. Drug Alcohol Depend. 2014;138:185-92. doi: 10.1016/j.drugalcdep.2014.02.705. [PubMed: 24679841].

13. van der Vorst H, Engels RC, Meeus W, Dekovic M. Parental attachment, parental control, and early development of alcohol use: A longitudinal study. Psychol Addict Behav. 2006;20(2):107-16. doi: 10.1037/0893164X.20.2.107. [PubMed: 16784352].

14. Fallu JS, Janosz M, Briere FN, Descheneaux A, Vitaro F, Tremblay RE. Preventing disruptive boys from becoming heavy substance users during adolescence: A longitudinal study of familial and peer-related protective factors. Addict Behav. 2010;35(12):1074-82. doi: 10.1016/j.addbeh.2010.07.008. [PubMed: 20688439].

15. Chuang YC, Ennett ST, Bauman KE, Foshee VA. Relationships of adolescents' perceptions of parental and peer behaviors with cigarette and alcohol use in different neighborhood contexts. J Youth Adolesc. 2009;38(10):1388-98. doi: 10.1007/s10964-009-9424-x. [PubMed: 19779814].

16. Hooper LM, Doehler K, Jankowski PJ, Tomek SE. Patterns of selfreported alcohol use, depressive symptoms, and body mass index in a family sample: The buffering effects of parentification. Family $J$. 2012;20(2):164-78. doi: 10.1177/1066480711435320.

17. Habibi R, Nikbakht Nasrabadi A, Shabany Hamedan M, Saleh Moqadam A. The effects of family-centered problem-solving education on relapse rate, self efficacy and self esteem among substance abusers. Int J High Risk Behav Addict. 2016;5(1). e24421. doi: 10.5812/ijhrba.24421. [PubMed: 27162761]. [PubMed Central: PMC4859933].

18. Pirsaraee HY. When parents use drugs: Key findings from qualitative research on parenting and children in Iran. Child Family Soc Work. 2007;12(2):113-22. doi:10.1111/j.1365-2206.2006.00449.x.

19. Mirlashari J, Demirkol A, Salsali M, Rafiey H, Jahanbani J. Early childhood experiences, parenting and the process of drug dependency among young people in Tehran, Iran. Drug Alcohol Rev. 2012;31(4):4618. doi: 10.1111/j.1465-3362.2011.00384.x. [PubMed: 22141922].

20. Hsieh HF, Shannon SE. Three approaches to qualitative content analysis. Qual Health Res. 2005;15(9):1277-88. doi: 10.1177/1049732305276687. [PubMed: 16204405].

21. Strauss A, Corbin J, Newbury Park CA. Basics of qualitative research: Grounded theory procedures and techniques. London: Sage Publications; 1990.

22. Seale C. The quality of qualitative research. Sage Publications; 1999.

23. Streubert HCD. Qualitative research in nursing. 3rd ed. Philadelphia: Lippincott Williams \& Wilkins; 2003.

24. Shahid H, Bhatt M, Sanger N, Zielinski L, Luo C, Bantoto B, et al. Association between family factors and illicit polysubstance use amongst methadone maintenance patients with opioid use disorder. Int J High Risk Behav Addict. 2018;7(4). doi: 10.5812/ijhrba.58786. 
25. Carlson MJ. Family structure, father involvement, and adolescent behavioral outcomes. J Marriage Fam. 2006;68(1):137-54. doi:10.1111/j.17413737.2006.00239.x

26. Taylor A. Working with parental substance misuse: Dilemmas for practice. Brit J Soc Work. 2004;34(8):1115-32. doi: 10.1093/bjsw/bch132.

27. George MR, Cummings EM, Davies PT. Positive aspects of fathering and mothering, and children's attachment in Kindergarten. Early Child Dev Care. 2010;180(1-2):107-19. doi:10.1080/03004430903414752. [PubMed: 20657740]. [PubMed Central: PMC2908248].

28. Biblarz TJ, Stacey J. How does the gender of parents matter? JMarriage Fam. 2010;72(1):3-22. doi: 10.1111/j.1741-3737.2009.00678.x.

29. Hagan J, Simpson J, Gillis AR. Feminist scholarship, relational and instrumental control, and a power-control theory of gender and delinquency. Br J Sociol.1988;39(3):301-36. [PubMed: 3179640].

30. Hoeben EM, Weerman FM. Why is involvement in unstructured socializing related to adolescent delinquency? Criminology. 2016;54(2):242-81. doi:10.1111/1745-9125.12105.

31. Khantzian EJ. The self-medication hypothesis of substance use disorders: A reconsideration and recent applications. Harv Rev Psychiatry. 1997;4(5):231-44. doi: 10.3109/10673229709030550. [PubMed: 9385000].
32. Andersen SL, Teicher MH. Desperately driven and no brakes: Developmental stress exposure and subsequent risk for substance abuse. Neurosci Biobehav Rev. 2009;33(4):516-24. doi: 10.1016/j.neubiorev.2008.09.009. [PubMed: 18938197]. [PubMed Central: PMC2688959].

33. Barrett AE, Turner RJ. Family structure and substance use problems in adolescence and early adulthood: examining explanations for the relationship. Addiction. 2006;101(1):109-20. doi: 10.1111/j.13600443.2005.01296.x. [PubMed: 16393197].

34. Elkington KS, Bauermeister JA, Zimmerman MA. Psychological distress, substance use, and HIV/STI risk behaviors among youth.J Youth Adolesc. 2010;39(5):514-27. doi: 10.1007/s10964-010-9524-7. [PubMed: 20229264]. [PubMed Central: PMC2855969].

35. Maynard BR, Salas-Wright CP, Vaughn MG. High school dropouts in emerging adulthood: Substance use, mental health problems, and crime. Community Ment Health J. 2015;51(3):289-99. doi:10.1007/s10597014-9760-5. [PubMed: 25030805]. [PubMed Central: PMC4655594].

36. Townsend L, Flisher AJ, King G. A systematic review of the relationship between high school dropout and substance use. Clin Child Fam Psychol Rev. 2007;10(4):295-317. doi: 10.1007/s10567-007-0023-7. [PubMed: 17636403]. 